4. Hagler DJ, Miranda WR, Haggerty BJ, Anderson JH, Johnson JN, Cetta F, et al. Fate of the Fontan connection: mechanisms of stenosis and management. Congenit Heart Dis. 2019;14:571-81.
5. d'Udekem Y, Thambo JB, Iyengar AJ, Rychik J. Are we getting closer to identifying the best follow-up and management after Fontan completion? J Thorac Cardiovasc Surg. July 4, 2020 [Epub ahead of print].
See Article page 372.

\section{Commentary: The heart of the matter: Close clinical follow-up and exercise capacity in Fontan circulation}

\author{
Andrew Well, MD, MPH, MSCHT, and \\ Ziv Beckerman, MD
}

In this issue of the Journal, Patel and colleagues ${ }^{1}$ evaluate the cross-sectional area (CSA) of extracardiac Fontan conduits and associated hemodynamic impact at various times during follow-up. The authors are to be commended for their compilation of a large number of patients with Fontan circulation (FC) with magnetic resonance imaging, catheter, and cardiopulmonary exercise testing (CPET) data. Their analysis revealed a median CSA decline of $68 \%$ compared with the original CSA of the conduit implanted. The decline in CSA was found to have no association with cardiac parameters; however, CSA indexed to body surface area was associated with percent predicted maximal oxygen uptake on CPET. These findings are consistent with previous computational modeling ${ }^{2}$ and a retrospective review from South Korea. ${ }^{3}$ It is insightful that no clear association was found between the implanted conduit size and the measured hemodynamic parameters. Surgeons frequently debate intraoperatively as to what size conduit to implant, with a bias toward trying to implant the largest conduit possible without causing distortion of surrounding structures.

From the Division of Pediatric and Congenital Cardiothoracic Surgery, Department of Surgery and Perioperative Care, University of Texas Dell Medical School, Austin, Tex; and Texas Center for Pediatric and Congenital Heart Disease, UT Health Austin/Dell Children's Medical Center, Austin, Tex.

Disclosures: The authors reported no conflicts of interest.

The Journal policy requires editors and reviewers to disclose conflicts of interest and to decline handling or reviewing manuscripts for which they may have a conflict of interest. The editors and reviewers of this article have no conflicts of interest.

Received for publication Oct 19, 2020; revisions received Oct 19, 2020; accepted for publication Oct 21, 2020; available ahead of print Oct 29, 2020

Address for reprints: Ziv Beckerman, MD, Texas Center for Pediatric and Congenital Heart Disease, Dell Children's Medical Center, 4900 Mueller Blvd, Suite 3S.003, Austin, TX 78723 (E-mail: zbeckerman@austin.utexas.edu).

J Thorac Cardiovasc Surg 2021;162:382-3

0022-5223/\$36.00

Copyright (c) 2020 by The American Association for Thoracic Surgery

https://doi.org/10.1016/j.jtcvs.2020.10.094

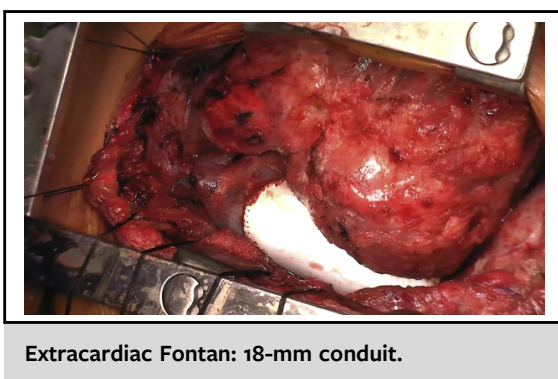

CENTRAL MESSAGE

Exercise capacity is an important outcome in patients who have undergone the Fontan. A review presents the importance of continued hemodynamic and exercise testing. Critical assessment of exercise testing is required.

Exercise capacity and CPET have been used as important outcomes in research of patients with FC. A prime example is the recent outcomes of the FUEL trial. ${ }^{4}$ CPET requires careful analysis and interpretation. Many challenges in the conduct and evaluation of CPET in patients with FC are highlighted in the manuscript from Patel and colleagues. ${ }^{1}$ CPET was performed by 2 methodologies: treadmill and cycle ergometry. There are inherent differences in these 2 methodologies with treadmill testing resulting in a mean of $9 \%$ and a maximum of $18 \%$ higher maximal oxygen uptake compared with cycle. ${ }^{5}$ Given this disparity, it is not advisable to combine the results of the 2 methods. An important characteristic to evaluate in CPET is the respiratory exchange ratio (RER), the ratio of carbon dioxide produced to oxygen consumed. In practice, the RER represents the effort put forth during the CPET with a RER 1.1 or more representing adequate effort while a RER 1 or less represents poor effort and validity of the maximal oxygen uptake should be questioned. ${ }^{6}$ As shown in the article by Patel and colleagues, the mean RER was 1.1, resulting in half of patients in the study having a CPET study in the sub-optimal range. It is important to note that a singular measurement of maximal oxygen uptake has not been consistently associated with 
mortality or hospitalizations in patients with $\mathrm{FC}{ }^{7}$ Maximal oxygen uptake evaluation becomes prognostic in $\mathrm{FC}$ when performed serially and reveals a decline over time. ${ }^{8}$

Beyond any prognostic ability, in ongoing research, the ability to keep up with peers physically has been identified as an important outcome to patients with FC. Given the dual importance of exercise capacity, it should continue to be used as a key outcome. This article by Patel and colleagues emphasizes the importance of long-term continuous clinical and hemodynamic evaluation of patients with FC. Ideally, in a prospective manner, with strict adherence to standardized CPET methodology. Predictors of decline in CPET measures and interventions to prevent decline and improve measures can result in great impact in directing care of patients with FC.

\section{References}

1. Patel ND, Friedman C, Herrington C, Wood JC, Cheng AL. Progression in Fontan conduit stenosis and hemodynamic impact during childhood and adolescence. $J$ Thorac Cardiovasc Surg. 2021;162:372-80.e2.
2. Itatani K, Miyaji K, Tomoyasu T, Nakahata Y, Ohara K, Takamoto S, et al. Optimal conduit size of the extracardiac Fontan operation based on energy loss and flow stagnation. Ann Thorac Surg. 2009;88:565-72.

3. Lee SY, Song MK, Kim GB, Bae EJ, Kim SH, Jang SI, et al. Relation between ex ercise capacity and extracardiac conduit size in patients with Fontan circulation. Pediatr Cardiol. 2019;40:1584-90.

4. Goldberg DJ, Zak V, Goldstein BH, Schumacher KR, Rhodes J, Penny DJ, et al Pediatric Heart Network Investigators. Results of the FUEL trial. Circulation. 2020;141:641-51.

5. Shephard RJ. Tests of maximum oxygen intake. A critical review. Sports Med. 1984;1:99-124.

6. Balady GJ, Arena R, Sietsema K, Myers J, Coke L, Fletcher GF, et al; American Heart Association Exercise, Cardiac Rehabilitation, and Prevention Committee of the Council on Clinical Cardiology, Council on Epidemiology and Prevention, Council on Peripheral Vascular Disease, Interdisciplinary Council on Quality of Care and Outcomes Research. Clinician's Guide to cardiopulmonary exercise testing in adults: a scientific statement from the American Heart Association. Circulation. 2010;122:191-225.

7. Udholm S, Aldweib N, Hjortdal VE, Veldtman GR. Prognostic power of cardiopulmonary exercise testing in Fontan patients: a systematic review. Open Heart. 2018;5:e000812.

8. Egbe AC, Driscoll DJ, Khan AR, Said SS, Akintoye E, Berganza FM, et al. Cardiopulmonary exercise test in adults with prior Fontan operation: the prognostic value of serial testing. Int J Cardiol. 2017;235:6-10.
See Article page 372

\section{Commentary: As we learn more, we know little}

\author{
Awais Ashfaq, MD, and James S. Tweddell, MD
}

The Fontan operation is the goal for patients with a single ventricle, and the procedure has undergone various modifications over the years. Originally introduced in $1990,{ }^{1}$ extracardiac conduit Fontan possesses some advantages such as improved flow dynamics, lower arrhythmias, and technically less challenging. Nonetheless, lack of growth potential and thrombogenecity are important drawbacks and lead to reinterventions. Patel and colleagues ${ }^{2}$ have provided us with an important study looking at the intermediate outcome of the extracardiac Fontan. The authors studied

\footnotetext{
From the Department of Cardiothoracic Surgery, Cincinnati Children's Hospital Medical Center, Cincinnati, Ohio.

Disclosures: The authors reported no conflicts of interest.

The Journal policy requires editors and reviewers to disclose conflicts of interest and to decline handling or reviewing manuscripts for which they may have a conflict of interest. The editors and reviewers of this article have no conflicts of interest.

Received for publication Oct 17, 2020; revisions received Oct 17, 2020; accepted for publication Oct 20, 2020; available ahead of print Oct 27, 2020.

Address for reprints: Awais Ashfaq, MD, Department of Cardiothoracic Surgery, Cincinnati Children's Hospital Medical Center, 3333 Burnett Ave, Cincinnati, OH 45229 (E-mail: awais.ashfaq@cchmc.org).

J Thorac Cardiovasc Surg 2021;162:383-4

$0022-5223 / \$ 36.00$

Copyright (c) 2020 by The American Association for Thoracic Surgery

https://doi.org/10.1016/j.jtcvs.2020.10.074
}

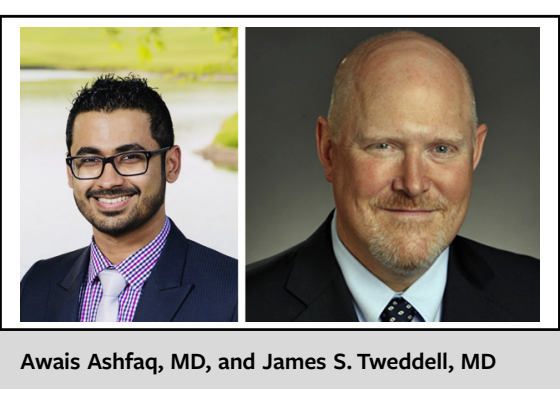

CENTRAL MESSAGE

Optimal Fontan conduit size continues to be unknown.
165 patients undergoing the extracardiac Fontan by magnetic resonance imaging over a span of 6 years. The results were discouraging. The Fontan cross-sectional area decreased in at least one-third of patients as early as 6 months postoperation, although there was no change thereafter. They found that patients had smaller than normal pulmonary arteries and there was an absence of pulmonary 